\title{
Introduction to the Advances in Design Science Research Minitrack
}

\author{
Richard Baskerville \\ Georgia State University \\ Curtin University \\ baskerville@gsu.edu
}

\author{
Matti Rossi \\ Aalto University \\ matti.rossi@aalto.fi
}

\author{
Tuure Tuunanen \\ University of Jyväskylä \\ tuure@tuunanen.fi
}

This minitrack provides a venue for design science researchers (DSR) to share their work and interact with likeminded scholars. DSR is a prominent form of engaged scholarship, which combines inquiry with a potential for action and intervention. DSR may be viewed as having three related subfields, from which we received submissions:

- Science of design, which focuses on creating 'new-to-the-world' artifacts [1-3]. We try to provide an outlet for researchers doing novel artifact driven research in information systems, but also in other fields such as industrial engineering or service design.

- Design theory studies, which focus on the development of theories about creating new or improved systems based on kernel or grand theories. The design theory concept was first articulated two decades ago $[4,5]$ and continues to be developed [6].

- Design Research, which focuses on the study of how designers actually conduct design activities, e.g., science of design research. Papers in this subfield could potentially come not only from IS, but also from architecture and design studies.

All three subfields are often (but not always) tightly engaged with design practice. Accordingly, they frequently embody participative forms of research that rest on the advice and perspectives of multiple stakeholders in understanding a complex social problem.

The building and application of designed artifacts in real settings produces knowledge and understanding of a problem domain and its solutions, which is then potentially transferable to other domains. In design science, the engagement is primarily focused on the design and evaluation of an artifact; learning through building and evolving it with the aim to generate theoretical insights. This is often an iterative research process and sometimes capitalizes on learning via both researcher and subject expertise within the context of the participants' social system. It can be a clinical method that puts IS researchers in an active supporting role for advanced practice.

Accordingly, in this mini track we have research contributions that arise from all three subfields of DSR described above. This includes engaged approaches, studies of the practical use of DSR approaches, the use of such approaches to expand theory, and conceptual foundations that significantly and cogently expand our understanding of the epistemology and methodology of such approaches and their philosophical underpinnings. These include:

- Developing design artifacts and design theories

- Evaluating and testing design artifacts and design theories

- Different approaches to the design of artifacts and design theorizing

- Design as a creative act in development for systems etc.

- Advancing theory and practice in designing for systems etc.

- Design experiences in organizational systems and technology etc.

- Concrete design projects and their outcomes

We received this year in total 14 submissions, of which we accepted 7 with an acceptance rate of $50 \%$. The articles are summarized in below:

Architecture of Belonging - A Social Identitybased Design Theory of Community Identification in Multiplayer Video Games by Bastian Kordyaka, Samuli Laato, Marius Müller, and Bjoern Niehaves. The paper constructs an explanatory design theory of community identification as a predictor of engagement in multiplayer online games. To that end, a mixedmethod study was conducted. First, a quantitative survey was used to illustrate the explanatory power of community identification and later a workshop was held identifying similarity and mutual influence as the most meaningful design elements of community identification. 
Dealers of Peaches and Lemons: How Can Used Car Dealers Use Trusted Car Data to create value? by Joachim Baumann, Liudmila Zavolokina, and Gerhard Schwabe. The paper looks at the used car market and the mistrust and uncertainties related this business. The authors propose three design principles addressing some of these problems. Their findings show that, by easing data access, increasing the efficiency of sales related processes, and expanding the competences of used car dealers, the industry can reinvent itself to be a provider of trusted car data that successfully renews the market.

The Design Towards a News Aggregator Subscription Service: Results from An Online Experiment by Erol Kazan, Tuure Tuunanen, Hadi Ghanbari, and Mengcheng Li. The authors continue to present further findings from the digital subscriptions service that they also reported last year. The authors conduct an online experiment to test the performance of different payment plans for a collaborative news aggregator service. Finally, the paper reports preliminary design principles for value creation and capture, which can be utilized for designing a commercial and collaborative news aggregator service.

Managing Boundary-Spanning Cognition Through Emergent Problem-Framing in Enterprise Systems Design by Susan Gasson. This paper presents findings from a study of codesign of business processes and IT systems at the enterprise level. These findings suggest a punctuated equilibrium model of boundaryspanning design that is driven by a series of coordinating representations of the design problem-structure.

Promoting Design Knowledge Accumulation Through Systematic Reuse: The Case for Product Line Engineering by Oscar Diaz, Haritz Medina, and Jeremias Perez Contell. The paper looks at design knowledge accumulation across DSR projects. The authors argue that, in order for design knowledge accumulation to thrive, it should be accompanied by DSR artifacts. More specifically, they advocate for complementing the relevance-design-rigor cycles with a fourth step: refactor and introduce reuse considerations for the DSR artifacts. They apply the concepts of product line engineering in three DSR projects.

Data Science Canvas: Evaluation of a Tool to Manage Data Science Projects by Thomas
Neifer, Dennis Lawo, and Margarita Esau. Based on a literature review, the authors identified influencing factors that are essential for the success of data science projects. The findings lead to development of a Data Science Canvas. To find out whether such an instrument could support data-driven value creation, the canvase was evaluated by practitioners in an expert workshop.

What Are They Talking about? Relation Extraction from News to Identify Research Directions in Emerging Technologies by Nicolas Prat. This paper examines how emerging technologies are characterized by their uncertainty, rapid evolution, and major impact. It proposes and applies a methodology that performs text mining on news crawled from the Internet in order to identify research directions for an emerging technology. The methodology uses relation extraction on the news documents to extract relations between terms of the emerging technology and information systems constructs.

\section{References}

[1] Hevner, A.R., March, S.T., and Park, J.: 'Design Research in Information Systems Research', MIS Quarterly, 2004, 28, (1), pp. 75-105

[2] Peffers, K., Tuunanen, T., Rothenberger, M., and Chatterjee, S.: 'A Design Science Research Methodology for Information Systems Research', Journal of Management Information Systems, 2008, 24, (3), pp. 4578

[3] Sein, M.K., Henfridsson, O., Purao, S., Rossi, M., and Lindgren, R.: 'Action Design Research', Mis Quarterly, 2011, 35, (1)

[4] Walls, J.G., Widmeyer, G.R., and El Sawy, O.A.: 'Building an information system design theory for vigilant EIS', Information systems research, 1992, 3, (1), pp. 36-59

[5] March, S.T., and Smith, G.F.: 'Design and natural science research on information technology', Decision support systems, 1995, 15, (4), pp. 251-266

[6] Gregor, S., and Hevner, A.R.: 'Positioning and presenting design science reseach for maximum impact', MIS Quarterly, 2013, 37, (2), pp. 337-355. 